\title{
ESTUDIO DE LA CALIDAD MICROBIOLOGICA Y FISICO QUIMICO DE LAS AGUAS DE CONSUMO EN EL DISTRITO DE SANTO TORIBIO, ANCASH.
}

EGMA MAYTA $H$. GILBERT MARIANO GRIMALDINA DIAZ.

Dpto. de Microbiología. Facultad de Ciencias Biológicas. UNMSM.

\begin{abstract}
RESUMEN
Las aguas de uso doméstico en los tres barrios del Distrito Santo Toribio, provienen de: Red de agua no sometida a tratamiento, manantiales, reservorios, arroyuelos, y no se realiza control sanitario permanente. El objetivo es conocer la calidad higiénica de las aguas y prevención. Se examinó 276 muestras, utilizando métodos cualitativos y cuantitativos de APHA, OMS y OPS. Los resultados indican que: El $46.4 \%$ son aptas para consumo y son aprovechados por 1,200 habitantes, pertenecen a red de aguas no sometidas a tratamiento y manantiales. El $53.6 \%$ no es aceptable para consumo y son utilizados por 800 pobladores, pertenecen a los reservorios y arroyuelos.
\end{abstract}

\section{SUMMARY}

Water samples for domestic use derived from three suburbs of Santo Toribio district were analiced. Water in Santo Toribio is not treated and it is from different origen.

Santo Toribio district is suolied for a steady run well, spring water, reservoirs and brooklets in which the sanitary control is not made. This study is conducted to know the quality of water and prevention of diseases.

We have examined 276 samples, using qualitative and quantitative methods according to the APHA, WHO (World Health Organization), OPS (Peruvian Health Organization), assessments thus the results are the following : $46.4 \%$ of samples coming from steady run well and spring water are able for the comsumption so 1,200 habitants use this water. $53.6 \%$ of samples coming from reservoirs and brooklets are not appropiated for

\section{INTRODUCCION}

Las aguas provenientes de red de agua no sometida a tratamiento, manantiales, reservorios y arroyuelos, destacan por su importancia en la región como fuente abastecedora para consumo humano directo de 2,000 pobladores. El uso es sin tratamiento alguno, están distribuídos en 03 barrios: Nahuinyacu, Quecuas y Huayrán; asimismo, estas aguas se utilizan en agricultura y en ganadería.

Sin embargo, hasta ahora no se le da debida atención, desde el punto de vista sanitario que garantice elementales condiciones de higiene, a pesar de saber que el agua es uno de los medios de difusión de microorganismos que pueden afectar la salud humana, animal y vegetales. Investigaciones en ese sentido, son escazos en nuestro medio, sólo algunos aportes de LOZANO (1979), MONTES (1986), CONDEZO (1986), OCHOA (1986), VARGAS (1986), NAVARRO (1988), entre otros; para la zona existe información de ONERN $(1972,1984,1985)$, aporta datos sobre la topografía, la climatología, usos de las aguas y otros de la Cuenca del Santa, y MAYTA (1988), menciona que las aguas de los manantiales de abastecimientos domésticos en el Distrito de Huaylas son aptas para consumo y no registran signos de contaminación.

Nuestro estudio tiene como objetivo conocer la calidad higiénica de las aguas y su prevención, con mayor énfasis en el análisis microbiológico, físico-químico de las aguas, variaciones y las relaciones con los puntos de muestreo.

Se reporta que la red de aguas no sometida a tratamiento y manantiales son aptas para consumo y lo utilizan 1,200 pobladores, sus características microbiológicas y físico-químicas se encuentran dentro de los límites permisibles recomendados; mientras que las aguas de los reservorios y arroyuelos no son aceptables por presentar contaminación, calificándola como agua de mala calidad para uso doméstico.

\section{MATERIAL Y METODOS}

Material. 
a.- Para trabajo de campo.- Plano catastral del Distrito, altímetro, materiales de vidrio, fichas de enumeración y encuestas.

b.- Para análisis físico-químico del agua.- Laboratorio portátil Labkit, termómetro simple graduado en grados centígrados, papel indicador $\mathrm{pH}$, material de vidrio y otros.

c.- Para análisis microbiológico del agua.- Materiales de vidrio, medios de cultivo de pre-enriquecimiento, enriquecimiento e implementos menores.

d.- Para trabajo de laboratorio.- En los análisis cualitativos y cuantitativos se examinó en base a medios de cultivo selectivos, baterías bioquímicas de medios de cultivo, microscopio compuesto, contador de colonias y otros.

\section{Métodos.}

a.- Ubicación de puntos de muestreo.- Se tomó como referencia la naturaleza de la fuente de agua y el número de personas abastecidas, siendo 10 puntos en total, distribuidos: a) Red de agua no sometido a tratamiento; origen (tanque), red de distribución y centro de consumo, b) Manantiales; origen y efluente a $1 \mathrm{~m}$., c) Reservorios; efluente, influente y afluente, y d) Arroyuelos; a 20 y $40 \mathrm{~m}$. de recorrido desde los manantiales; obteniéndose un total de 276 muestras, recolectadas en los meses Febrero, Junio, Setiembre y Diciembre de 1991.

b.- Aspectos microbiológicos del agua.- Las muestras por punto de muestreo fueron obtenidas entre las $06 \mathrm{a}$ 08.00 hrs. (A.M.) en frascos de vidrio de color ambar de 1 lt. de capacidad, e inmediatamente transportadas a un laboratorio provisional en Santo Toribio para su siembra en medios de cultivo de cuantificación y preenriquecimiento. Cada muestra es procesada y rotulada, siguiendo las normas y recomendaciones de APHA (1975 - 1985), OPS (1988).

Se consideraron como indicadores de contaminación fecal a coliformes totales, coliformes fecales, Estreptococos fecales y se complementan las pruebas por el número de microorganismos aerobios viables, presencia de hongos y levaduras.

Las muestras pre-enriquecidas se trasladaron en cajas térmicas, con material refrigerante (hielo seco) a Lima. En el laboratorio de Microbiología de la Facultad de Ciencias Biológicas se realizan los estudios complementarios, de acuerdo a las normas recomendadas.

c.- Aspectos físico-químicos del agua.- $\mathrm{Al}$ obtener las muestras de aguain situ, para estudio microbiológico, se registró conjuntamente datos físico-químicos del recurso hídrico en base a las metodologías y técnicas recomendadas por APHA (1985) y OMS-OPS (1984).

\section{RESULTADOS Y DISCUSION}

\section{I.- Análisis cuantitativos. (ver tabla 1)}

A.- Red de agua no sometida a tratamiento.- El promedio de microorganismos viables oscila de 200 a 300 UFC/ml., para los puntos de muestreo de origen, distribución y consumo; en el grupo de coliformes el 100 $\%$ de las muestras resultaron negativas y ausencia de levaduras y hongos, características que nos indican que las aguas no están expuestas a contaminación ambiental y reune las condiciones mínimas de calidad higiénica, según ITINTEC (1987).

Cabe referir que estas aguas están protegidas por una infraestructura hidráulica (material noble), desde su origen (agua subterránea), que es almacenada en un tanque de $2 \times 2 \times 6$ m., luego las aguas son distribuidas por redes de tuberías, hasta los domicilios (centros de consumo). Asimismo, según las encuestas a los usuarios, nos manifiestan que se trata de agua potable, sin embargo estas aguas no son tratadas por las instituciones y autoridades pertinentes.

B.- Manantiales.- Se evaluaron 11 manantiales que correspondieron a 88 muestras, sea del origen y efluente $(1 \mathrm{~m}$. de distancia aguas abajo), el $100 \%$ de los análisis fueron negativos en el grupo de coliformes; el promedio de microorganismos aerobios viables fluctúa de 200 a 400 $\mathrm{UFC} / \mathrm{ml}$., valores que nos indica que las aguas son aptas para consumo, sus concentraciones se encuentran por debajo del límite permisible de las normas establecidas. La buena calidad de las aguas de los crenótopos, se debe al manejo y cuidado de estos, así tenemos que algunos manantiales han sido protegidos empíricamente por los usuarios, con piedras, maderas y tapas de cemento, evitando de este modo la contaminación ambiental y la relación directa con los organismos pecuarios. Asimismo es de resaltar que los manantiales tienden a cambiar algunas características físicas y biológicas durante la época de lluvias (Enero, Febrero y Marzo), tal es el cambio de color aparente de incoloro-amarillo a marrón-rojizo y presencia de hongos y levaduras, y se debe principalmente al ingreso de aguas de lluvias con material erosionado de los alrededores.

C.- Reservorios (pozos) de almacenamiento de aguas y arroyuelos.

Los reservorios son estructuras construidas de formas circulares y rectangulares, con manpostería de piedras y otros de arena-cemento, su finalidad es almacenar aguas, que provienen de manantiales localizados en el mismo reservorio y otros a distancia de 100 a $300 \mathrm{~m}$. que forman los arroyuelos, estas aguas se emplean principalmente para agricultura (irrigaciones) y pecuaria; sin embargo el $25 \%$ de la población utiliza para la preparación de alimentos y otros. 
Tabla 1: $\quad$ Resultados promedios de los Análisis Cuantitativos Microbiológicos de las aguas de consumo del Distrito Santo Toribio - 1991

\begin{tabular}{|c|c|c|c|c|c|c|c|}
\hline \multirow{2}{*}{$\begin{array}{l}\text { Indicadores Microbiológicos } \\
\text { Aguas de Consumo } \\
\text { Provenientes de }\end{array}$} & C.T & C.F & E.F & M.A.V & M.A.F & R.H & R.L \\
\hline & \multicolumn{3}{|c|}{ NMP/100 ml. } & \multicolumn{4}{|c|}{$\mathrm{UFC} / \mathrm{ml}$. } \\
\hline $\begin{array}{l}\text { - Red de agua no sometidas } \\
\text { a tratamiento }\end{array}$ & 2 & 2 & 3 & $2 \times 10^{2}$ & 30 & 0 & 0 \\
\hline - Origen (tanque) & 2 & 2 & 3 & $2 \times 10^{2}$ & 20 & 0 & 0 \\
\hline - Red distribución & 2 & 2 & 3 & $2 \times 10^{2}$ & 30 & 0 & 0 \\
\hline - Centro Consumo & 2 & 2 & 3 & $3 \times 10^{3}$ & 20 & 0 & 0 \\
\hline \multicolumn{8}{|l|}{ - Manantiales: 11} \\
\hline - Origen & 2 & 2 & 3 & $2 \times 10^{2}$ & 20 & 0 & 0 \\
\hline - Efluente & 4 & 2 & 3 & $4 \times 10^{2}$ & 30 & 3 & 5 \\
\hline \multicolumn{8}{|l|}{ - Reservorios: 10} \\
\hline - Afluente & 6 & 4 & 7.3 & $32 \times 10^{3}$ & 520 & 10 & 12 \\
\hline - Influente & 10 & 6 & 11 & $48 \times 10^{3}$ & 22,000 & 13 & 14 \\
\hline - Efluente & 15 & 4 & 7.2 & $43 \times 10^{2}$ & 1,900 & 10 & 10 \\
\hline \multirow{3}{*}{$\begin{array}{l}\text { - Arroyuelos: } \\
\text { - a } 20 \mathrm{~m} \text {. de } \\
\text { distancia. } \\
\text { - a } 40 \mathrm{~m} \text {. de } \\
\text { distancia }\end{array}$} & & & & & & & \\
\hline & 7 & 4 & 3.6 & $6 \times 10^{3}$ & 1,800 & 7 & 9 \\
\hline & 7 & 6 & 7.3 & $2 \times 10^{4}$ & 350 & 10 & 10 \\
\hline \multicolumn{8}{|l|}{$\begin{array}{l}\text { C.T. }=\text { Coliformes Totales } \\
\text { C.F. = Coliformes Fecales } \\
\text { E.F.= Estreptococos Fecales } \\
\text { M.A.V.= Microorganismo Ae } \\
\text { M.A.F.= Microorganismo Ae } \\
\text { R.H.= Recuentos de Hongos } \\
\text { R.L.= Recuentos de Levadura }\end{array}$} \\
\hline
\end{tabular}

Del estudio de 148 muestras pertenecientes a 10 reservorios y 07 arroyuelos, donde las aguas sirven de bebida a los pobladores, el número de microorganismos aerobios viables en la mayoría de las muestras supera el límite permisible (500 UFC/ml.), hongos y levaduras presentes en rango de 07 a $14 \mathrm{UFC} / \mathrm{ml}$., indicándonos elevada contaminación y no ser apta para consumo, comprometiendo sus usos posteriores en la agricultura (plantas de tallo corto y pecuario).

De las encuestas ejecutadas a los pobladores de los 03 barrios que consumen estas aguas, nos resulta que el $40 \%$ de entrevistados, padecen de problemas gastrointestinales, principalmente los niños, permitiendo que los afectados acudan al Centro de Salud y otros se mejoren con el uso directo de medicamentos, tratamientos simples y plantas medicinales para infecciones estomacales.

Cabe mencionar que si se toma en consideración las condiciones y las relaciones entre coliformes fecales y Estreptococos fecales, según GELDREICH Y KENNER (1969) para determinar el origen de la contaminación, es posible presumir que los cursos de agua tienen contaminación fecal, tanto humana y animal, principalmente de cerdos, ovejas, perros, entre otros, que abundan en la zona y se sustenta más con SUMMER (1967) y BUTTER and BUSBEE (1967), donde mencionan que en excrementos de animales de sangre caliente existe presencia de organismos patógenos, principalmente para el hombre.

\section{II.- Análisis cualitativos.}

De las 276 muestras de agua que se estudiaron, el $53.64 \%$ reveló contaminación por gérmenes patógenos: Pseudomonas aeruginosa, Salmonella typhi y Staphylococcus aureus, estos se registraron en los arroyuelos y reservorios, sobresaliendo los primeros y se debe a descargas orgánicas, producto de las actividades urbanas y animales; excedentes de riego que aportarían sedimentos y materia orgánica; pesticidas, fertilizantes, etc. efecto de la erosión originado por malas prácticas de cultivo. Otras bacterias que revelaron contaminación fecal y se aislaron fueron Escherichia coli tipo I, organismo indicador; Estreptococcus sp. y Proteus sp. 
entre otras. También se observó contaminación por la presencia y desarrollo de hongos y levaduras, constituyendo estas aguas un riesgo potencial para la salud de la población humana.

\section{III.- Análisis físico-químico de las aguas.}

a.- Físico.- Los crenótopos y potamótopos en su mayoría presentan lecho de sustrato franco rocoso, arenoso y blando, con sedimentación limosa. Los reservorios y arroyuelos con abundante sedimentación a base de materia orgánica proveniente de actividades urbanas, restos vegetales, de residuos o desperdicios. El color aparente de las aguas es incoloro y de transparencia total, su temperatura superficial flúctua de 12 a $16^{\circ} \mathrm{C}$, en algunos cuerpos de agua ésta temperatura es mayor a la temperatura ambiental, el caudal es variado e influyen las precipitaciones pluviales y manejo de las actividades de los reservorios por el hombre que usan en las irrigaciones de productos agropecuarios, siendo el mínimo de 5 l/seg.

b.- Químico.- El oxigeno disuelto varió de 2.00 a 6.5 ppm, siendo mayor en los arroyuelos que en los manantiales y tienden a saturarse a los $70 \%$. El anhidrido carbónico libre es ausente en algunos cuerpos de agua y en los crenótopos oscila de 2.5 a 18.4 ppm., estos se incrementan, debido a que éstas aguas son subterráneas. $\mathrm{El} \mathrm{pH}$ de las aguas flúctua de 6.5 a 7.0, indicando que se trata de aguas ligeramente ácidas con tendencia a la neutralidad. Los aniones de carbonatos e hidróxidos están ausentes, las reservas alcalinas varía en rango de 100 a 140 ppm como $\mathrm{CaCO}_{3}$. La dureza de las aguas oscila de 40 a 86 ppm. para el calcio, de 06 a 16 ppm en el magnesio y de 46 a 102 ppm como $\mathrm{CaCO}^{3}$, para el total, valores que nos indican que las aguas son semiduras. Los registros de cloruros, amonios y fosfatos, variaron en rangos de 35 a $80,0.50$ a 0.75 y 0.025 a $0.250 \mathrm{ppm}$, respectivamente.

Por las normas establecidas de ITINTEC (1987), las características físico-químicas, registradas en estas aguas de uso doméstico, nos indica, que los valores se encuentran dentro de los límites permisibles aptas para consumo humano.

\section{CONCLUSIONES Y RECOMENDACIONES}

1.- Se determinó que de 276 muestras estudiadas, 128 pertenecen a la red no sometida a tratamiento y manantiales, registran estar aptas para consumo; y $148 \mathrm{de}$ ellos, corresponde a los arroyuelos y reservorios, sus aguas no reunen las condiciones mínimas de calidad higiénica.

2.- El $53.64 \%$ de las muestras estudiadas reveló contaminación por E. coli, indicador de contaminación fecal.

3.- La inexistencia de servicios higiénicos públicos y desagues, afluencia masiva de los pobladores, existencia de animales de sangre caliente, excedentes de riego y efecto de la erosión originado por malas prácticas de cultivo, contribuyen a deteriorar los arroyuelos y reservorios.

4.- El $40 \%$ de la población utilizan en bebida aguas provenientes de los arroyuelos y reservorios y sufren problemas gastrointestinales, especialmente niños; sin embargo, pueden usarse para riego de vegetales de tallo alto, bebida de animales y crianza de Astroblepus simonsi.

5.- A fin de impedir la transmisión de los microorganismos fecales enteropatógenos presentes en lás aguas de los reservorios y arroyuelos a los ususarios y provocar infecciones; se recomienda utilizar aguas hervidas, tanto para la ingestión directa y lavado de fruta, vegetales y utensilios para comer. Asimismo los niños no deben bañarse y asearse con estas aguas.

6.- A fin de conservar las aguas de los manantiales que son de buena calidad en su mayoría de estos, localizados en los barrios: Ñahuinyaku, Quecuas y Huayrán, se recomienda proteger de inmediato a los manantiales con obras de ingeniería adecuada, en su origen y distribución, los usuarios obligatoriamente deben recurrir y obtener sus aguas de los crenótopos; asimismo, las autoridades de salud en coordinación con las autoridades edilicias, deben realizar un control sanitario permenente de las aguas en general para uso doméstico.

\section{REFERENCIAS BIBLIOGRAFICAS}

APHA. 1985. Métodos Standar para exámen de aguas de deshecho. 16ava Ed.

BUTTER, C. E. \& BUSBEE, C. E. 1967. Human Enteric Pathogens in Dogs in Fairbanks, Alaska. Pub. Health Reports 82:465.

CETESB. 1984. Coliformes Totais o Fecais. Determinacae de número mais prevvel pela tecnica de tubos multiples. Normalizacae técnica 211-10. 1ra. Revisao.

CONDEZO, S. G. Lagunas de Estabilización: Evaluación Bacteriológica. VIII Congreso Nacional de Biología. 25 al 31 de Octubre. 1986. Arequipa.

DECRETO SUPREMO No 007-83 S.A Ley General de Aguas: El Peruano 17-3-83.

ENVIRONMENTAL PROTECTION AGENCY. 1976. Quality Criteria Water. U.S. EPA, Washington D.C.

FUKUSHIMA, N. M. Y col.. 1971 Métodos Limnológicos. Trujillo-UNT. 
INSTITUTO DE INVESTIGACION TECNOLOGIA INDUSTRIAL Y DE NORMAS TECNICAS. 1987. Control Microbiológico de las Aguas y Requisitos Básicos. Normas 214.003 y 214.009 Junio. Perú.

MAYTA, H.E. y Col. 1988. Estudios Microbiológicos de los Manantiales de Abastecimientos Domésticos en el Distrito de Huaylas. IX Cong. Nac. de Biología. Piura - Perú.

MINISTERIO DE SALUD PUBLICA. 1982. Enfermedades Transmisibles. Cuadros Estadísticos Perú.

MONTES, D. M. L. 1986. Formación de Compuestos Carcinógenos Durante el Proceso de Tratamiento del Agua Potable. VIII Cong. Nac. de Biología. Arequipa- Perú. LOZANO, C. L. 1979. Análisis Bacteriológico del Agua Potable de Lima. Inf. Tec. UPCH.

NAVARRO, D. S. 1988. La Contaminación del río Cunas por Presencia de Coliformes. Tesis para optar el Título de Lic. en Pedagogia. UNCP - Huancayo.
OFICINA PANAMERICANA DE SALUD. 1985. Guías para la Calidad del Agua Potable. Vol. 1: Recomendaciones. Pub. $\mathrm{N}^{\circ}$ 481. Washington.

ORGANISMO MUNDIAL DE LA SALUD. 1s Normas Internacionales para el Agua Potable. 3ra. Edic. Ginebra.

OCHOA, O. M. y Col. 1986. Determinación de Coliformes y Enterococos en Agua de Piscinas en la Ciudad del Cuzco. VIII Cong. Nac. de Biología. Arequipa - Perú.

SUMMER, J. L. 1967. The Sanitary Significance of Pollution of Water by Domestic and Wild Animals. Lecture Review. USPHS.

VARGAS, C. C. A. 1986. Contribución al Estudio Microbiológico de las Aguas de las Cascadas de Barranco. VIII Cong. Nac. de Biología. Arequipa - Perú. 